\title{
Pengambilan Keputusan Dalam Penerima Bantuan Raskin Dengan Metode Simple Additive Weigthing (SAW)
}

\author{
Mia Hismawati ${ }^{1}$, Hardiyan² \\ 1STMIK Nusa Mandiri Jakarta \\ hismawatidevin@yahoo.com \\ ${ }^{2}$ AMIK BSI Tangerang \\ hardiyan.hry@bsi.ac.id
}

\begin{abstract}
Abstrak
Kemiskinan adalah keadaan di mana terjadi ketidakmampuan untuk memenuhi kebutuhan dasar seperti makanan, pakaian, tempat berlindung, pendidikan, dan kesehatan. Program Raskin ini merupakan subsidi pangan sebagai upaya dari Pemerintah untuk meningkatkan ketahanan pangan dan memberikan perlindungan pada keluarga miskin melalui pendistribusian beras yang diharapkan mampu menjangkau keluarga miskin. Dan sebagai upaya peningkatan ketahanan pangan di tingkat keluarga melalui penjualan beras kepada keluarga penerima manfaat pada tingkat harga bersubsidi dengan jumlah yang telah ditentukan dan mengurangi beban pengeluaran rumah tangga sasaran melalui pemenuhan sebagian kebutuhan pangan pokok dalam bentuk beras. Adapun model metode yang akan digunakan adalah metode Simple Additive Weighting (SAW). Metode ini merupakan metode dengan cara mencari penjumlahan terbobot dari rating kinerja pada setiap alternatif dan pada setiap atribut. Metode Simple Additive Weighting (SAW) dapat membantu dalam pengambilan keputusan suatu kasus, akan tetapi perhitungan dengan menggunakan metode ini hanya yang menghasilkan nilai terbesar yang akan terpilih sebagai alternatif yang terbaik.
\end{abstract}

Kata Kunci : Raskin, Simple Additive Weighting (SAW)

\begin{abstract}
Poverty is one of the problems that cannot be resolved and left unchecked. Poverty is also a condition in which a person is unable to fulfill basic needs such as clothing, food, shelter. The government's efforts in dealing with the problem of poverty are by holding various kinds of social assistance programs for the community so that they are expected to ease the burden of their daily needs. One of them is the Raskin program, this Raskin program is a food subsidy as an effort from the government to improve food security and provide protection to poor families through the distribution of rice which is expected to reach poor families. And as an effort to improve food security at the family level through the sale of rice to beneficiary families at subsidized price levels with a predetermined amount and reduce the target household expenditure burden by fulfilling a portion of staple food needs in the form of rice. The model method used is the Simple Additive Weighting (SAW) method. This Method is a method of finding the weighted sum of performance ratings on each alternative and on each attribute. Simple Additive Weighting (SAW) method can help in decision making of a case, but the calculation using this method only produces the biggest value that will be chosen as the best alternative.
\end{abstract}

Keywords: Raskin, Simple Additive Weighting (SAW)

Diterima Mei 02, 2018; Revisi Mei 25 , 2018; Disetujui Agustus 20, 2018 


\section{Pendahuluan}

Dari zaman pemerintahan dahulu hingga sekarang, setiap tahun pemerintah selalu mengeluarkan anggaran dana untuk berbagai macam program bantuan sosial baik berupa pendidikan, kesehatan, maupun bahan pangan ke setiap daerah-daerah untuk menekan angka kemiskinan yang ada di Indonesia. Bantuan Raskin (Beras untuk rakyat miskin) merupakan salah satu contoh program bantuan sosial yang diselenggarakan oleh pemerintah melalui Badan Pusat Statistik (BPS) yang diperuntukan bagi rumah tangga miskin dan rentan.Berdasarkan keputusan Menteri Koordinator Bidang Kesejahteraan Rakyat Nomor 54 Tahun 2014 tentang Pedoman Umum Raskin yaitu penetapan penerima manfaat program raskin di desa atau kelurahan menggunakan mekanisme musyawarah desa atau kelurahan yang dilaksanakan secara transparan dan partisipatif.

Kelurahan Pasir Jaya berada di alamat $\mathrm{Jl}$. Gajah Tunggal Kp. Pasir Jaya Kota Tangerang. Kelurahan ini terbagi atas 33 rukun tetangga dan 6 rukun warga, kelurahan ini merupakan salah satu instansi pemerintahan yang betugas dalam pelayanan masyarakat dan sebagai titik pendistribusian program raskin serta pengajuan daftar nama keluarga penerima program raskin.

Oleh karena itu penulis mencoba menerapkan suatu metode perhitungan yang dapat memperhitungkan segala kriteria yang menjadi solusi alternatif dalam proses pengambilan keputusan. Adapun model metode yang akan digunakan adalah metode Simple Additive Weighting (SAW). Metode ini merupakan metode dengan cara mencari penjumlahan terbobot dari rating kinerja pada setiap alternatif dan pada setiap atribut. Metode Simple Additive Weighting (SAW) dapat membantu dalam pengambilan keputusan suatu kasus, akan tetapi perhitungan dengan menggunakan metode ini hanya yang menghasilkan nilai terbesar yang akan terpilih sebagai alternatif yang terbaik.

\section{Tinjauan Pustaka}

\section{Simple Additive Weighting (SAW)}

Menurut Fishburn dan MacCrimmon dalam (Frieyadie, 2016) menjelaskan bahwa: "Metode SAW (Simple Additive Weighting) sering juga dikenal istilah metode penjumlahan terbobot. Konsep dasar metode SAW adalah mencari penjumlahan terbobot dari rating kinerja pada setiap alternatif pada semua atribut."

Adapun langkah penyelesaian suatu masalah menggunakan metode Simple Additive Weighting menurut Nofriansyah dalam (Hidayat, 2017) yaitu

1. Menentukan kriteria yang akan diajadikan acuan dalam pengambilan keputusan yaitu $\mathrm{Ci}$.

2. Memberikan nilai bobot untuk masing-masing kriteria sebagai $W$.

3. Memberikan nilai rating kecocokan setiap alternatif pada setiap alternatif.

4. Membuat matriks keputusan berdasarkan kriteria (Ci), kemudian melakukan normalisasi matriks berdasarkan persamaan yang disesuaikan dengan jenis atribut (atribut keuntungan ataupun atribut biaya) sehingga diperoleh matriks ternormalisasi $R$.

$$
\mathrm{r} \square=\left\{\begin{array}{l}
\frac{\mathrm{x} \square}{\operatorname{Max}(\mathrm{x} \square)} \\
\frac{\operatorname{Min}(\mathrm{x} \square)}{\mathrm{x} \square}
\end{array}\right.
$$

Keterangan :

rij = nilai rating kinerja ternormalisasi.

$X_{i j}=$ nilai atribut yang dimiliki dari setiap kriteria.

Max $\mathrm{Xij}=$ nilai terbesar dari setiap kriteria.

Min Xij = nilai terkecil dari setiap kriteria.

Benefit $=$ jika nilai terbesar adalah terbaik.

5. Hasil akhir diperoleh dari proses perankingan yaitu penjumlahan dan perkalian matriks ternormalisasi $\mathrm{R}$ dengan vector bobot sehingga diperoleh nilai terbesar yang dipilih sebagai alternatif yang terbaik ( $\mathrm{Ai}$ ) sebagai solusi.

$$
V=\sum_{j=1}^{n} w \square r \square
$$

Keterangan :

$\mathrm{Vi}=$ ranking untuk setiap alternative.

$\mathrm{Wj}=$ nilai bobot dari setiap kriteria.

rij = nilai rating kinerja ternormalisasi

\section{Kelebihan dari Metode Simple Additive Weighting (SAW)}

Menurut Darmastuti dalam (Siswono, Bahiyah, \& Sokibi, 2017) Kelebihan dari model Simple Additive Weighting (SAW) dibandingkan dengan model pengambilan keputusan yang lain terletak pada kemampuannya untuk melakukan penilaian secara lebih tepat karena didasarkan pada nilai kriteria dan bobot preferensi yang sudah ditentukan, selain itu SAW juga dapat menyeleksi alternatif terbaik dari sejumlah alternatif yang ada karena adanya proses 
perankingan setelah menentukan nilai bobot untuk setiap atribut.

\section{Metode Penelitian Tahapan Penelitian}

Tahapan penelitian mencakup langkahlangkah pelaksanaan penelitian dari awal hingga akhir menurut (Rusdiansyah, 2017) yaitu :

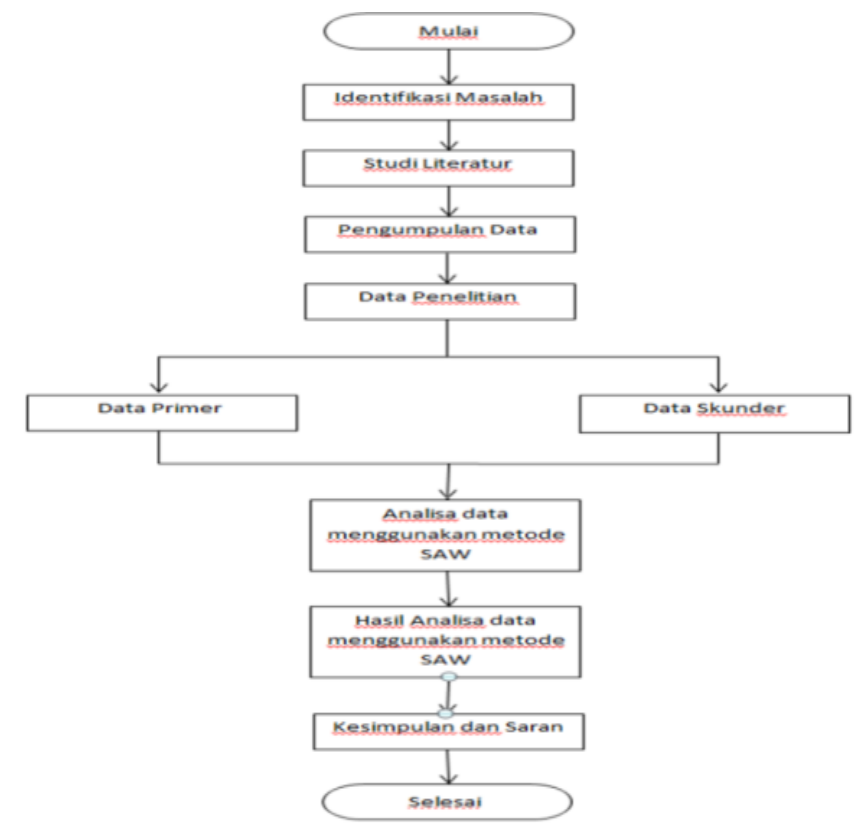

Gambar 1. Tahapan Penelitian

Sumber: Rusdiansyah (2017)

1. Identifikasi Masalah

Melakukan identifikasi pada suatu masalah merupakan tahap awal pada proses penelitian. Tahap ini dibangun berdasarkan rumusan masalah yang didasari atas latar belakang masalah.

2. Studi literatur

Dilakukan dengan mempelajari dan memahami teori-teori yang digunakan, yaitu diantaranya mencari faktor-faktor yang menjadi syarat penggunaan Metode Simple Additive Weighting (SAW) dan metode pengumpulan data. Data-data tersebut dicari dengan cara mengumpulkan literatur, jurnal nasional, browsing internet dan bacaan-bacaan yang ada kaitannya dengan topik baik berupa textbook atau paper.

3. Pengumpulan Data

Tahap ini merupakan cara mengumpulkan data yang dilakukan dengan dua cara, yaitu observasi dan wawancara kepada pihak Kelurahan terkait parameter menentukan keluarga penerima raskin.
4. Data Penelitian

Dalam penelitian ini data yang dibutuhkan dibagi menjadi dua yaitu data primer dan data skunder.

5. Analisa Data Menggunakan Metode Simple Additive Weighting (SAW)

Analisa data dalam penelitian ini menggunakan metode Simple Additive Weighting (SAW) yang digunakan secara kuantitatif yaitu metode penelitian yang bersikap deskriptif dan lebih banyak menggunakan analisis.Penelitian ini dilakukan dengan mengumpulkan data dan hasil analisis untuk mendapatkan informasi yang harus disimpulkan.

6. Hasil Analisa Data Menggunakan Metode Simple Additive Weighting (SAW)

Setelah tahap analisis data dengan menggunakan metode Simple Additive Weighting (SAW) dihasilkan suatu hasil analisis yang merupakan hasil dari suatu proses penelitian yang dilakukan.

7. Kesimpulan dan Saran

Kesimpulan merupakan tahapan akhir dari uraian proses penelitian dengan menyimpulkan permasalahan yang ada.

\section{Instrumen Penelitian}

Instrumen penelitian Menurut Sugiarti dalam (Rusdiansyah, 2017) dapat disimpulkan "Semua alat yang digunakan untuk mengumpulkan, mengolah, menganalisa dan menyajikan data-data secara sistematis serta objektif dengan tujuan memecahkan suatu persoalan atau menguji suatu hipotesis."

Teknik wawancara dilakukukan kepada lurah seputar penerimaan bantuan raskin yang ada di kelurahan berdasarkan instrument yang dibuat. Tidak hanya itu, dilakukan wawancara dengan seksi kemasyarakatan yang berkaitan dengan penerima bantuan raskin dengan memberikan kuesioner berdasarkan data yang didapat dan data dari kuesioner tersebut dapat dengan cepat dianalisis. Data hasil uji coba dianalisis secara deskriptif. Data tersebut meliputi skor menentukan keluarga penerima raskin berdasarkan Pekerjaan, Penghasilan, Jumlah Tanggungan Keluarga, Umur dan Pendidikan..

\section{Metode Pengumpulan Data}

Menurut Susanti dalam (Rusdiansyah, 2017) "Metode pengumpulan data merupakan faktor penting demi keberhasilan penelitian."

Berikut merupakan metode pengumpulan data yang dilakukan: 
a. Data Primer

Dalam pengumpulan data primer dalam penelitian ini menggunakan metode observasi dan wawancara.

1. Observasi

Melakukan pengamatan di Kelurahan terhadap alur kerja yang dilakukan dan dicatat secara sistematis untuk kemudian dipelajari sehingga mendapatkan materimateri yang dibutuhkan.

2. Wawancara

Menurut Sugiyono dalam (Nugroho \& Hardiyan, 2016) mendefinisikan : "Wawancara digunakan sebagai teknik pengumpulan data apabila peneliti akan melaksanakan studi pendahuluan untuk menemukan permasalahan yang harus diteliti, dan juga peneliti ingin mengetahui hal-hal dari responden yang lebih mendalam dan jumlah respondennya sedikit/kecil".

Yang di wawancarai adalah pihak-pihak yang terkait secara langsung dengan pelaksanaan program raskin yaitu $\mathrm{lbu} \mathrm{Hj}$. Dwi Purwanti selaku seksi kemasyarakatan di Kelurahan Pasir Jaya.

a. Data Sekunder

Data sekunder ini didapatkan melalui dokumentasi, literatur, buku, jurnal ilmiah, buku referensi, dan segala informasi lainnya terkait.

\section{Populasi, Sample dan Sampling Jenuh}

Menurut (Sugiyono, 2017:80) "Populasi adalah wilayah generalisasi yang terdiri atas : obyek / subyek yang mempunyai kualitas dan karakteristik tertentu yang ditetapkan oleh peneliti untuk dipelajari dan kemudian ditarik kesimpulannya."

Tehnik sampel yang digunakan adalah NonProbability Sampling. Adapun tehnik yangdigunakan yaitu Sampling Sistematis. Dalam penerima raskin ini anggota populasi yang menerima bantuan terdiri dari 150 orang.Dari semua anggota itu telah diberi nomor urut, yaitu nomor 1 sampai dengan nomor 150.Penulis mengambil sampel dengan menggunakan nomor ganjil kelipatan 5. Dan jumlah responden yang di ambil adalah 1 orang untuk mengisi pertanyaan yang penulis berikan sesuai data yang ada. Dan sampel yang penulis ambil berjumlah 30 orang dari 150 populasi yang ada.
Tabel 1. Profil Sampel

\begin{tabular}{|l|l|}
\hline \multicolumn{1}{|c|}{ Nama Warga } & Kode Warga \\
\hline Andi & A1 \\
\hline Budi Setiono & A2 \\
\hline Uci Sanusi & A3 \\
\hline Yudowati & A4 \\
\hline Muhammad Arifin & A5 \\
\hline Dedi Herifin & A6 \\
\hline Juhra & A7 \\
\hline Tri Mardiyanti & A8 \\
\hline Romlah & A9 \\
\hline Mufrodi & A10 \\
\hline Madromi & A11 \\
\hline Usman & A12 \\
\hline Alimi & A13 \\
\hline Madhadi & A14 \\
\hline Dede Wahyudin & A15 \\
\hline Gusambrizal & A16 \\
\hline Sukemi & A17 \\
\hline Holili & A18 \\
\hline Yulyana & A19 \\
\hline Irwan Jaya & A20 \\
\hline M. Edy Syamsudin & A21 \\
\hline Farida & A22 \\
\hline Sumanto & A23 \\
\hline Ester Megawati & A24 \\
\hline Mahpud & A25 \\
\hline Arman Munandar & A25 \\
\hline Rusdin & A27 \\
\hline Muhammad Abdullah & A28 \\
\hline Sholikin Ali Said & A29 \\
\hline Dedi Ramadhan & A30 \\
\hline Sumber: Kelurahan Pasir & Jay 2018 \\
\hline
\end{tabular}

Sumber : Kelurahan Pasir Jaya (2018)

\section{Hasil dan Pembahasan}

\section{Pengolahan Data Menggunakan Metode Simple Additive Weighting}

Terdapat beberapa langkah untuk melakukan perhitungan penilaian keluarga terbaik penerima raskin menggunakan metode Simple Additive Weighting (SAW) :

1. Kriteria Bobot

Dalam perhitungan ini dibutuhkan kriteriakriteria untuk menentukan penilaian keluarga terbaik penerima raskin. Dari masing-masing 
kriteria tersebut akan ditentukan bobot-bobotnya dan kriteria yang dibutuhkan dalam pengambilan keputusan dapat dilihat pada tabel 2 , sebagai berikut :

\begin{tabular}{|l|l|l|}
\hline $4-5$ Orang & Sedang & 3 \\
\hline $6-7$ Orang & Rendah & 4 \\
\hline$>$ 8Orang & Sangat Rendah & 5 \\
\hline
\end{tabular}

Sumber : Olah data (2018)

c. Kriteria Umur (C4)

Tabel 6. Umur

\begin{tabular}{|c|l|}
\hline Kriteria ( C ) & \multicolumn{1}{c|}{ Keterangan } \\
\hline C1 & Pekerjaan \\
\hline C2 & Penghasilan \\
\hline C3 & Jumlah Tanggungan Keluarga \\
\hline C4 & Umur \\
\hline C5 & Pendidikan \\
\hline
\end{tabular}

Sumber : Olah data (2018)

Adapun kriteria yang dilakukan oleh penulis dalam penelitian keluarga terbaik penerima raskin, yaitu sebagai berikut :

a. Kriteria Pekerjaan (C1)

Tabel 3. Pekerjaan

\begin{tabular}{|l|l|c|}
\hline \multicolumn{1}{|c|}{ Pekerjaan } & \multicolumn{1}{c|}{ Keterangan } & Nilai \\
\hline Wiraswasta & Sangat Tinggi & 1 \\
\hline PNS & Tinggi & 2 \\
\hline $\begin{array}{l}\text { Karyawan } \\
\text { Swasta }\end{array}$ & Sedang & 3 \\
\hline $\begin{array}{l}\text { Harian Lepas } \\
(\mathrm{HL})\end{array}$ & Rendah & 4 \\
\hline Tidak Bekerja & $\begin{array}{l}\text { Sangat } \\
\text { Rendah }\end{array}$ & 5 \\
\hline
\end{tabular}

Sumber : Olah data (2018)

Tabel 4. Penghasilan

\begin{tabular}{|l|l|l|}
\hline \multicolumn{1}{|c|}{ Penghasilan } & Keterangan & \multicolumn{1}{c|}{ Nilai } \\
\hline$>$ dari 5.000.000 & Sangat Tinggi & 1 \\
\hline $\begin{array}{l}3.000 .000- \\
5.000 .000\end{array}$ & Tinggi & 2 \\
\hline $1.000 .000-$ & Sedang & 3 \\
3.000 .000 & & \\
\hline $500.000-$ & Rendah & 4 \\
1.000 .000 & $\begin{array}{l}\text { Sangat } \\
\text { Rendah }\end{array}$ & 5 \\
\hline$<$ dari 500.000 & \\
\hline
\end{tabular}

Sumber : Olah data (2018)

b. Kriteria Jumlah Tanggungan Keluarga (C3)

Tabel 5. Jumlah Tanggungan Keluarga

\begin{tabular}{|l|l|c|}
\hline $\begin{array}{c}\text { Jumlah } \\
\text { Tanggungan } \\
\text { Keluarga }\end{array}$ & \multicolumn{1}{|c|}{ Keterangan } & Nilai \\
\hline 1 Orang & Sangat Tinggi & 1 \\
\hline $2-3$ Orang & Tinggi & 2 \\
\hline
\end{tabular}

Tabel 7. Pendidikan

\begin{tabular}{|l|l|l|}
\hline \multicolumn{1}{|c|}{ Pendidikan } & \multicolumn{1}{c|}{ Keterangan } & Nilai \\
\hline D3 - S1 & Sangat Tinggi & 1 \\
\hline SMA/SMK & Tinggi & 2 \\
\hline SMP & Sedang & 3 \\
\hline SD & Rendah & 4 \\
\hline Tidak Sekolah & Sangat Rendah & 5 \\
\hline
\end{tabular}

Sumber : Olah data (2018)

Nilai perhitungan untuk setiap warga dengan nilai $V_{i}$ dapat dilihat pada tabel berikut :

Table 8. Hasil Perangkingan

\begin{tabular}{|l|c|c|}
\hline \multicolumn{1}{|c|}{$\begin{array}{c}\text { Nama } \\
\text { Warga }\end{array}$} & $\begin{array}{c}\text { Kode } \\
\text { Warga }\end{array}$ & $\begin{array}{c}\text { Hasil } \\
\text { Perangkingan }\end{array}$ \\
\hline Andi & A1 & 0,5875 \\
\hline Budi Setiono & A2 & 0,5375 \\
\hline Uci Sanusi & A3 & 0,4825 \\
\hline Yudowati & A4 & 0,6725 \\
\hline $\begin{array}{l}\text { Muhammad } \\
\text { Arifin }\end{array}$ & A5 & 0,625 \\
\hline Dedi Herifin & A6 & 0,4825 \\
\hline Juhra & A7 & 0,3425 \\
\hline Tri Mardiyanti & A8 & 0,655 \\
\hline Romlah & A9 & 0,625 \\
\hline Mufrodi & A10 & 0,52 \\
\hline Madromi & A11 & 0,4275 \\
\hline Usman & A12 & 0,4175 \\
\hline Alimi & A13 & 0,5375 \\
\hline Madhadi & A14 & 0,675 \\
\hline $\begin{array}{l}\text { Dede } \\
\text { Wahyudin }\end{array}$ & A15 & 0,615 \\
\hline Gusambrizal & A16 & 0,4275 \\
\hline Sukemi & A17 & 0,4225 \\
\hline Holili & A18 & 0,41375 \\
\hline
\end{tabular}




\begin{tabular}{|l|c|c|}
\hline Yulyana & A19 & 0,645 \\
\hline Irwan Jaya & A20 & 0,4275 \\
\hline $\begin{array}{l}\text { M. Edy } \\
\text { Syamsudin }\end{array}$ & A21 & 0,4325 \\
\hline Farida & A22 & 0,6425 \\
\hline Sumanto & A23 & 0,5175 \\
\hline $\begin{array}{l}\text { Ester } \\
\text { Megawati }\end{array}$ & A24 & 0,6875 \\
\hline Mahpud & A25 & 0,5375 \\
\hline $\begin{array}{l}\text { Arman } \\
\text { Munandar }\end{array}$ & A26 & 0,4425 \\
\hline Rusdin & A27 & 0,4675 \\
\hline $\begin{array}{l}\text { Muhammad } \\
\text { Abdullah }\end{array}$ & A28 & 0,6075 \\
\hline $\begin{array}{l}\text { Sholikin Ali } \\
\text { Said }\end{array}$ & A29 & 0,4325 \\
\hline $\begin{array}{l}\text { Dedi } \\
\text { Ramadhan }\end{array}$ & A30 & 0,5175 \\
\hline
\end{tabular}

Sumber : Hasil olah data (2018)

Nilai terbesar ada pada V24 sehingga alternatif A24 adalah alternatif terbaik dengan hasil akhir = 0,6875 .

Nilai terbesar ada pada V24 sehingga alternatif A24 adalah alternatif terbaik dengan hasil akhir = 0,6875 . Untuk mengetahui siapa saja yang pantas menerima yaitu dengan menentukan skor total yang diperoleh dari jawaban kuisioner kemudian hasil skor tersebut dihitung seperti dibawah ini :

$=\frac{\text { Total Skor Kuesioner }}{\text { jumlah pilihanx jumlah pertanyaan xjumlah responder }} \times 100 \%$

$=\frac{968}{5 \times 5 \times a 0} \times 100 \%$

\section{$=0,49$ atau $49 \%$}

Pada perhitungan tersebut dikatakan pantas menerima raskin jika hasil kuisioner berada pada interval $>=49 \%$ dan dikatakan tidak pantas menerima raskin jika hasilnya berada pada interval $<49 \%$. Berikut ini adalah data 17 orang yang pantas menerima bantuan raskin :

Table 9. Data Penerima Raskin

\begin{tabular}{|l|l|l|l|}
\hline No & \multicolumn{1}{|c|}{ Nama } & \multicolumn{1}{|c|}{ Nilai } & $\begin{array}{c}\text { Persentase } \\
(\%)\end{array}$ \\
\hline 1 & Ester Megawati & 0,6875 & $68 \%$ \\
\hline 2 & Madhadi & 0,675 & $67 \%$ \\
\hline 3 & Yudowati & 0,6725 & $67 \%$ \\
\hline 4 & Tri Mardiyanti & 0,655 & $65 \%$ \\
\hline 5 & Yulyana & 0,645 & $64 \%$ \\
\hline 6 & Farida & 0,6425 & $64 \%$ \\
\hline 7 & Muhammad & 0,625 & $64 \%$ \\
\hline
\end{tabular}

\begin{tabular}{|l|l|l|l|}
\hline & Arifin & & \\
\hline 8 & Romlah & 0,625 & $62 \%$ \\
\hline 9 & Dede Wahyudin & 0,615 & $61 \%$ \\
\hline 10 & $\begin{array}{l}\text { Muhammad } \\
\text { Abdullah }\end{array}$ & 0,6075 & $60 \%$ \\
\hline 11 & Andi & 0,5875 & $58 \%$ \\
\hline 12 & Budi Setiono & 0,5375 & $53 \%$ \\
\hline 13 & Alimi & 0,5375 & $53 \%$ \\
\hline 14 & Mahpud & 0,5375 & $53 \%$ \\
\hline 15 & Mufrodi & 0,52 & $52 \%$ \\
\hline 16 & Sumanto & 0,5175 & $51 \%$ \\
\hline 17 & Dedi Ramadhan & 0,5175 & $51 \%$ \\
\hline
\end{tabular}

Sumber : Hasil olah data (2018)

\section{Kesimpulan}

Dari hasil penelitian Penerapan Metode Simple Additive Weighting (SAW) Pada Penerima BantuanRaskin dapat diambil beberapa kesimpulan diantaranya sebagai berikut:

1. Dari perhitungan dengan menggunakan metode Simple Additive Weight (SAW) dengan acuan kriteria pekerjaan, penghasilan, jumlah tanggungan keluarga, umur dan pendidikan, maka terpilih seorang warga dengan nilai tertinggi yaitu bernama Ester Megawati dengan perolehan nilai sebesar 0,6875.

2. Berdasarkan perhitungan dengan menggunakan metode Simple Additive Weight (SAW) dan hasil kuesioner jumlah warga yang pantas menerima bantuan raskin yaitu 17 orang.

3. Dengan penerapan metode Simple Additive Weighting (SAW) menghasilkan solusi alternatif terbaik dalam penyelesaian dan perhitungan dengan nilai-nilai kriteria yang dimiliki tiap warga, sehingga diketahui hasil yang akurat dalam proses penerima bantuan raskin.

\section{Referensi}

Frieyadie. (2016). Penerapan Metode Simple Additive Weight (Saw) Dalam Sistem Pendukung Keputusan Promosi Kenaikan Jabatan. Jurnal Pilar Nusa Mandiri, 12(1), 37-45. Retrieved from http://ejournal.nusamandiri.ac.id/ejurnal/inde x.php/pilar/article/view/70/67\#

Hidayat, R. (2017). Sistem Pendukung Keputusan Penerima Beasiswa Murid Berprestasi dengan Metode Simple Additive Weighting. Jurnal Sisfotek Global, 7(2), 1317. Retrieved from https://stmikglobal.ac.id/journal/index.php/sis fotek/article/view/147/151 
Nugroho, N., \& Hardiyan. (2016). Decision Support System ( Dss ) Dalam Pengangkatan Pelatih Pencak Silat Gerak Saka Dengan Metode Analytical Hierarchy Process (AHP), XIII(2), 89-95.

Rusdiansyah. (2017). Analisis Keputusan Menentukan Jurusan Pada Sekolah Menengah Kejuruan Dengan Metode Simple Additive Weighting. Jurnal Techno Nusa Mandiri, 14(1), 49-56. Retrieved from http://ejournal.nusamandiri.ac.id/ejurnal/inde x.php/techno/article/view/397/303

Siswono, A., Bahiyah, N., \& Sokibi, P. (2017). Untuk Menentukan Kelayakan Penerima Program Raskin Menggunakan Metode Simple Additive Weighting ( Saw ) Pada Kelurahan Kesambi, 7(1), 62-73.

Sugiyono, P. D. (2017). Metode Penelitian Kuantitatif, Kualitatif, dan R\&D (25th ed.). Bandung: Alfabeta. 